\title{
High-Density Fiber Optical Sensor and Instrumentation for Gas Turbine Operation Condition Monitoring
}

\author{
Hua Xia, ${ }^{1,2}$ Doug Byrd, ${ }^{3}$ Sachin Dekate, ${ }^{1}$ and Boon Lee ${ }^{1}$ \\ ${ }^{1}$ Photonics Laboratory, Micro and Nano Structures Technologies, GE Global Research, 1 Research Circle, Niskayuna, NY 12309, USA \\ ${ }^{2}$ College of Nanoscale Science and Engineering, State University of New York at Albany, NY 12222, USA \\ ${ }^{3}$ Engineering Division, GE Energy, 300 Garlington Road, GTTC 200D, Greenville, SC 29615, USA
}

Correspondence should be addressed to Hua Xia; hxia@albany.edu

Received 30 October 2012; Accepted 28 January 2013

Academic Editor: Joao Batista Rosolem

Copyright (c) 2013 Hua Xia et al. This is an open access article distributed under the Creative Commons Attribution License, which permits unrestricted use, distribution, and reproduction in any medium, provided the original work is properly cited.

\begin{abstract}
Gas turbine operation control is normally based on thermocouple-measured exhaust temperatures. Due to radiation shielding and bulky package, it is difficult to provide high spatial resolution for measuring can-to-can combustion temperature profile at the exhaust duct. This paper has demonstrated that wavelength-division-multiplexing-based fiber Bragg grating sensors could provide high spatial resolution steady and dynamic temperature measurements. A robust sensor package can be designed with either circumferential sensing cable or radial sensing rake for quasi-distributing multiple fiber sensors in the gas turbine environment. The field validations have demonstrated that quasi-distributed fiber sensors have not only demonstrated its temperature measurement accuracy compared to existing thermocouple sensors but also shown its unique dynamic response amplitude and power spectra that could be utilized for gas turbine transient operation condition monitoring and diagnostics.
\end{abstract}

\section{Introduction}

Accurate static and dynamic temperature detections are essential for safe and efficient operation and control in many industrial machinery systems, which include but are not limited to gas turbine, steam generator, boiler, combustor, compressor, gasifier, and so forth. In combustion control practice, an annular array of thermocouples is used to measure exhaust temperature profile, which is then used to ensure safe operation of the gas turbine. Whenever a fault temperature, either too cold or too hot, is detected, a gas turbine shutdown is initiated, which in many cases could be premature. Such a gas turbine operational control method requires accurate annular exhaust static and dynamic temperature measurement. Obviously, the purpose of the static and dynamic temperature detection is either for realtime industrial process monitoring and diagnostics or for operation control and optimization.

Since gas temperature is one of the critical measurement parameters for gas turbine operation, improvements of the temperature measurement accuracies can improve turbine efficiency. Direct combustor temperature measurement is highly desirable for robust turbine design and operation, but normally this requirement is beyond the capabilities of most thermocouple sensors. Therefore, most OEMs opt to use exhaust gas temperature measurement as a surrogate. Current exhaust temperature measurement using the annular array of thermocouples (TCs) provides limited discrete sensing points, and the sensing spatial resolution is not optimal. Accordingly, a conservative control and operation strategy of the gas turbine is warranted, which has a limiting effect on the gas turbine performance. A potential solution is to increase the number of thermocouples and improve their spatial arrangement. However, it is difficult to increase the number and location of the existing TCs from the current method due to their bulky packaging and excessive electrical wiring needs. Fiber Bragg grating (FBG) sensors are thought to be of great potential for temperature measurement in the harsh environments such as turbomachinery systems because of the advantages as having low mass, high sensitivity, 
multiplexing capabilities, multipoint distribution capabilities, multisensing functions, and electromagnetic interference immunity $[1,2]$.

A FBG is basically sensitive to both strain and temperature variations [3], but it can be packaged for static temperature measurement with so-called "loss package" or freestanding package method $[4,5]$. However, a so-called "prestrain package" method could be used for measuring structural instability or dynamic signal. In the presurge condition for a gas turbine or compressor, such packaged fiber sensors could be used to measure temperature variation rates or thermal spikes either at the gas inlet or downstream exhaust. A sensing cable normally consists of a plurality of fiber sensors that have to be sealed in a metal, ceramic, or polymeric tube or capillary, depending upon the sensing environmental conditions. A sensing instrumentation is constructed by multiplexing different arrays or sensing cables either with multichannel optical sensing interrogator [e.g., Micron Optics $1 \mathrm{~Hz}$ sm125/1 kHz sm130, http://www.micronoptics.com/] or with an optical sensing interrogator plus an optical-switcherbased multiplexer [e.g., Micron Optics, sm041]. The static and dynamic signals from FBG sensors are analyzed either with time-division or with wavelength-division multiplexing method, or their combination.

This paper has presented recent progress in applying fiber sensors and instrumentation for measuring gas turbine exhaust temperature at both startup and steady operation conditions with wavelength-division multiplexing technology. For circumferential exhaust temperature detection from a gas turbine, FBG sensing elements are inscribed onto a single fiber with a spatial separation of $450 \mathrm{~mm}$; three sensing fibers with $150 \mathrm{~mm}$ misplacement provide double spatial resolution for 9FB gas turbine exhaust temperature profile detection. For radial exhaust temperature detection, a precision exhaust temperature rake is used to support FBG sensors as an integrated radial sensing rake with $100 \mathrm{~mm}$ spatial resolution across exhaust duct wall to central barrier space. The obtained static wavelength data (1 data per second) are converted to temperatures with a precalibrated transfer function, while the dynamic wavelength data (1000 data per second) are analyzed to catch vibration modes and system displacement amplitude with fast Fourier transform algorithm.

\section{High-Density Fiber Temperature Sensor}

It is understood that a grating is a telecom filter device for wavelength multiplexing or demultiplexing applications; it is absolute not a temperature sensor despite its intrinsic natures of temperature and strain dependence. Conventional Type-I FBG has been used in various infrastructural healthmonitoring applications $[6,7]$. However, this type of FBG has poor thermal survivability and accuracy degradation at relative elevated temperature of greater than $300^{\circ} \mathrm{C}$. Research has shown that some Type-IIA, Type-II, regenerated FBGs (fabricated either by ultraviolet lasers or femtosecond lasers), and chiral gratings have also shown survivability even at $1000-1100^{\circ} \mathrm{C}$ [8-13]. With thermal stable FBGs, they can be used as temperature sensor. In addition, a mechanical package has to be properly designed for maintaining FBG sensor's integrity, survivability, functionality, and durability $[4,5]$.

FBG elements used in this work have used high-power ultraviolet (UV) laser with a phase mask technology for inscribing Bragg grating in a single-mode fiber core [12, 13]. This forms a periodic mass density-modulated grating pattern that can be characterized by a Bragg resonant peak at

$$
\lambda_{B}=2 \cdot n_{\mathrm{eff}} \cdot \Lambda(\rho)
$$

where the effective refractive index $n_{\text {eff }}$ in the fiber core includes the laser-inscription-process-produced refractive index modulation, $n$, and mass density modulation induced refractive index $n_{\rho}$. The thermal dependence of a Bragg grating can be described by

$$
\begin{array}{r}
\Delta \lambda=\lambda_{B} \cdot\left[\kappa_{\varepsilon} \cdot \varepsilon+\left(\beta+\alpha+\frac{1}{n_{\mathrm{eff}}} \frac{\partial n_{\rho}}{\partial T}\right) \cdot \Delta T\right. \\
\left.+\left(\frac{1}{n_{\mathrm{eff}}} \frac{\partial n_{\rho}}{\partial t}+\frac{1}{\Lambda} \frac{\partial \Lambda}{\partial t}\right) \Delta t\right],
\end{array}
$$

where $\alpha$ is the coefficient of fiber thermal expansion, $\lambda_{B} \cdot \kappa_{\varepsilon}$ is the strain sensitivity $(\sim 1.2 \mathrm{pm} / \mu \varepsilon), \beta$ is the thermooptic coefficient, and the $\Delta t$ reflects the time-dependent fiber material microstructure relaxation process. For low-density Type-I FBGs, the temperature dependence of the FBG Bragg resonant wavelength can be simply expressed as

$$
\begin{aligned}
\Delta \lambda(t) & =\lambda_{B} \cdot\left[\kappa_{\varepsilon} \cdot \varepsilon+(\beta+\alpha) \cdot T(t)-T(0)\right] \\
& =a(0)+a(1) \cdot \Delta T(t),
\end{aligned}
$$

where $a(0)$ can be treated as an offset to initial wavelength shift, and $\kappa_{T}(0)=\lambda_{B} \cdot(\beta+\alpha)$ is defined as temperature sensitivity. For low-temperature application, the FBG has a linear response to external temperature by

$$
\Delta \lambda(t)=\lambda(t)-\lambda_{B}(0)-a(0)=a(1) \cdot[T(t)-T(0)],
$$

where $a(1)=\kappa_{T}(0)=\lambda_{B} \cdot(\beta+\alpha) \approx 10-12 \mathrm{pm} /{ }^{\circ} \mathrm{C}$. High-density FBG is more or less related to compact fiber material with mass density and refractive index comodulation in the fiber core, induced by laser inscription process. Specifically, the operation at elevated temperature could turn an amorphous floppy microstructure of the fiber material to a nanocrystalline even microcrystalline morphology. With such a structural transition, the FBG thermal response function can be also described by

$$
\begin{aligned}
\Delta \lambda(t) & =\lambda_{B} \cdot\left[\kappa_{\varepsilon} \cdot \varepsilon+\left(\beta+\alpha+\beta_{\rho}\right) \cdot \Delta T+(1+\xi) \cdot\left|\frac{\Delta \rho}{\rho}\right|\right] \\
& =b(0)+b(1) \cdot \Delta T
\end{aligned}
$$

where $0.2<\xi<0.3$. This equation describes the fiber material which has experienced a structural transition 


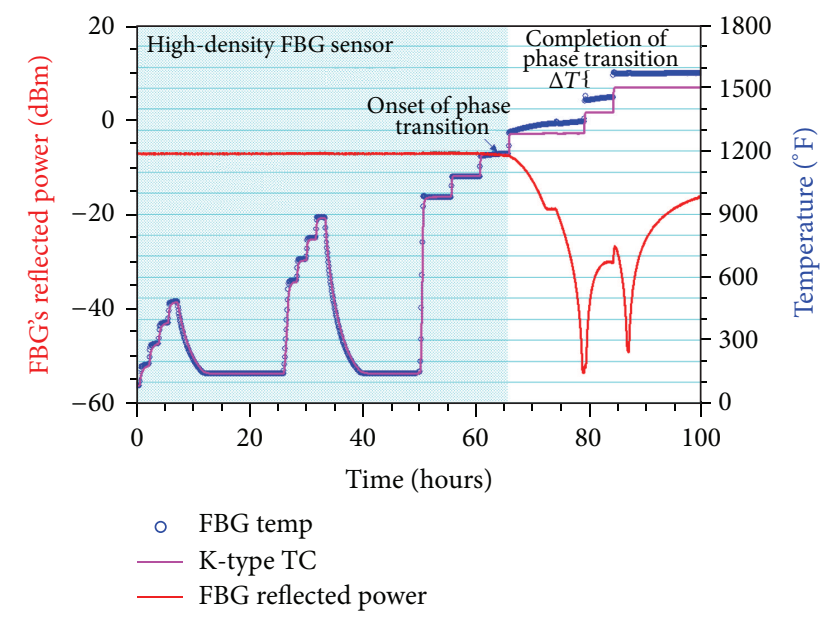

FIGURE 1: Fiber sensor response to external temperature change from ambient to $500^{\circ} \mathrm{F}, 900^{\circ} \mathrm{F}, 1200^{\circ} \mathrm{F}$ (shaded area), and beyond its maximum operation temperature of $1200^{\circ} \mathrm{F}$.

with a baseline upshift determined by fiber material density change. Note that the temperature sensitivity has an additional term, where $\kappa_{T}=\lambda_{B} \cdot\left(\alpha+\beta+\beta_{\rho}\right)$. When $\beta_{\rho}>0$, the temperature sensitivity $\kappa_{T}$ at high-density phase will be greater than the low-density phase $\kappa_{T}(0)=\lambda_{B} \cdot(\alpha+\beta)$, as seen from most of regenerated and Type-II FBGs with $\kappa_{T} \sim$ $14-16 \mathrm{pm} /{ }^{\circ} \mathrm{C}$. For femtosecond inscribed FBGs in pure silica or sapphire fibers, the temperature sensitivity $\kappa_{T}$ is $\lambda_{B} \cdot\left(\alpha+\beta_{\rho}\right)$, where $\beta_{\rho}$ depends mostly upon the used fiber material and laser power level or irradiation energy. Moreover, (5) could be rewritten as (4) and this would approximate the inherent nature of the fiber sensor response, determined by external temperature.

The FBG elements used in this paper were fabricated with high-power ultraviolet (UV) laser with a phase mask technology on a single-mode fiber material. The fiber material and inscription process can be found from [14], which has summarized detailed grating fabrication process. The obtained FBG elements will follow a postthermal annealing process to stabilize material structural morphology. Figure 1 has shown a typical high-density-FBG-based temperature sensor and its comparison with thermocouple measurement in three temperature ranges. First is from ambient to $500^{\circ} \mathrm{F}$, second is from ambient to $900^{\circ} \mathrm{F}$, and third is from ambient to $\sim 1200^{\circ} \mathrm{F}\left(\sim 650^{\circ} \mathrm{C}\right)$ and beyond. Since the fiber material microstructure has been stabilized previously annealing temperature at $1200 \circ \mathrm{F}$, a maximum allowed temperature, the wavelength shift beyond $1200^{\circ} \mathrm{F}$ (as in shaded area) will not correspond to real temperature because the fiber material microstructure or morphology is transforming into another thermal stabilized state. From $1200^{\circ} \mathrm{F}$ to $1500^{\circ} \mathrm{F}$, accompanying the fiber material structural transition, the FBG's reflected power has experienced a dramatic variation, and the Bragg resonant wavelength eventually stabilized at $1500^{\circ} \mathrm{F}$, which is defined as a new maximum allowed temperature. Obviously, this fiber material morphology transition has resulted in an offset of $\Delta T \sim 80^{\circ} \mathrm{F}$ than real temperature, which is unacceptable for any machinery system control because of this material physical phenomenon if the FBG is operated up to $1500^{\circ} \mathrm{F}$. It should be pointed out that the observed "dips" in the FBG's reflected power are more or less related to socalled grating regeneration process, similar to described in $[2,5,13]$. However, to guarantee a FBG sensor's accuracy and reliability, the maximum operation temperature is normally $10 \%$ less than its maximum allowed temperature. However, if a pulsed and short-term thermal shock occurs than the maximum allowed temperature, the deterioration of the fiber sensor's accuracy may be not noticeable. On the contrary, a new calibration is required for recovering FBG temperature accuracy by correcting the fiber material phase transition induced density and refractive index variations.

\section{Fiber Temperature Sensor Calibration and Performance}

Before its use as a temperature sensor, a FBG has to be calibrated to obtain a so-called transfer function for converting the relative measured Bragg resonant wavelength shift to relative temperature change, as shown in (4)-(5). On the other hand, a transfer function may be invalid if the fiber material is experiencing microstructural transition process, which occurs at $T>570^{\circ} \mathrm{C}$ for Type-I FBGs and $T>$ $870^{\circ} \mathrm{C}$ for Type-II FBG. Whenever this situation occurs, a new calibration process will be required to ensure the measurement accuracy. That is because the wavelength shift of the FBG is no longer associated with temperature. Specifically, when the fiber material is experiencing a microstructural transition, its temperature sensing function is temporarily lost until a new fiber microstructure is thermally stabilized. Afterwards, the FBG can be again used as a temperature sensor with a new calibrated transfer function, as discussed in the previous section. Calibration process of the FBG versus standard temperature gauge can be done in a programmable furnace. FBGs and standard temperature gauge are installed inside the furnace chamber where the temperature profile is uniform. The maximum allowed temperature is defined as about $10 \%$ higher than the desired operation temperature. Between the lowest and maximum operation temperature range, at least 10 data points corresponding to isothermal values will be required for extracting transfer function. After such a calibration process, the obtained transfer function can be used directly to convert wavelength shift to temperature by embedding it into the software.

To calibrate the Bragg resonant wavelength shift of a FBG against a standard thermometer, it is normally to measure both signals in the temperature range of interested under an isothermal process. For high accurate temperature measurement, a resistance temperature detector (RTD) or precision resistance thermometer (PRT) could provide better than $\pm 0.2^{\circ} \mathrm{C}$ accuracy while $\mathrm{k}$-Type $\mathrm{TC}$ only provides $\pm 1^{\circ} \mathrm{C}$ accuracy. RTD and PRT are popular because of their excellent stability and exhibit the most linear signal with respect to temperature of any electronic temperature sensor. They are generally more expensive than alternatives, however, because of the careful construction and use of platinum. They are also characterized by a slow response time, low sensitivity, and 
limited operation temperature $\left(650^{\circ} \mathrm{C}\right)$. However, an RTD or PRT is commonly characterized by nonlinear quadric or cubic polynomial function of $R_{T}=R_{0}\left[1+a \cdot T+b \cdot T^{2}+c \cdot T^{3}\right]$ or $R_{T}=R_{0} \cdot\left[1+a \cdot T+b \cdot T^{2}\right]$, where $R_{T}$ is resistance at temperature $T, R_{0}$ is nominal resistance, and $a, b$, and $c$ are constants used to scale the RTD or PRT.

For fiber sensor calibration, on the other hand, a transfer function is not always linear as (4)-(5). For high-temperature sensing application, the thermooptic coefficient is a nonlinear function of temperature:

$$
\beta_{\mathrm{eff}} \equiv \beta+\beta_{\rho}=A+B \cdot \Delta T+C \cdot \Delta T^{2},
$$

where $\beta_{\text {eff }}$ may be positive or negative depending upon fiber material and wavelength and $A, B$, and $C$ are constants. The associated transfer function of the Bragg wavelength shift to temperature will have a similar form of cubic polynomial function for high-density FBG sensors:

$$
\begin{gathered}
\Delta \lambda(T)=a(0)+a(1) \cdot \Delta T+a(2) \cdot \Delta T^{2}+a(3) \cdot \Delta T^{3} \\
a(0)=\lambda_{B} \cdot\left(\kappa_{\varepsilon} \cdot \varepsilon+(1+\xi) \cdot\left|\frac{\Delta \rho}{\rho}\right|\right), \\
a(1)=\lambda_{B} \cdot(A+\alpha), \quad a(2)=\lambda_{B} \cdot B, \quad a(3)=\lambda_{B} \cdot C .
\end{gathered}
$$

For temperature $T<200^{\circ} \mathrm{C}$, the $\mathrm{FBG}$ sensor response can be approximately expressed by $\Delta \lambda(T)=a(0)+a(1) \cdot \Delta T$, where $a(1) \approx \kappa_{T}$ is low-density FBG temperature sensitivity. The nonlinear equation (7), however, is regarded as a generic transfer function for accurate wavelength conversion for a broad temperature range measurement. It should be pointed out that $a(0)$ term in (7) reflects both strain effect and potential fiber material compactness or/and phase transition induced mass density contributions. Whenever an FBG sensor has experienced extreme temperature or suffered from package-related strain effects, the $a(0)$ could be changed, which leads to a temperature bias. In another word, (7) is only valid to be used for a constant strain thermal stabilized FBG, which either has not experienced any morphology change or the microstructural transitions have been fully completed.

The thermal response of FBG elements is measured with an optical sensing interrogator [MOI $1 \mathrm{~Hz}, \mathrm{sm} 125-500 / \mathrm{sm} 041$ channel multiplexer], in which the wavelength can be tuned from $1510 \mathrm{~nm}$ to $1590 \mathrm{~nm}$ with $\pm 1 \mathrm{pm}$ accuracy. A LabVIEWbased software automatically identifies FBG peak position and saves both peak wavelength and converted temperature values. Figure 2(a) has shown a typical FBG spectrum with its Bragg resonant wavelength at $1544.75 \mathrm{~nm}$ and peak power of $-7.26 \mathrm{dBm}$ at ambient. This wavelength is upshifted, following the furnace temperatures as seen in Figure 2(b). The isothermal values from FBG (blue lines) and from thermocouple (TC) (red lines) are plotted in Figure 2(c) and fitted to a cubic polynomial function. The obtained coefficients are used to convert FBG wavelength shift values to temperatures (in circles). Figure 2(d) has plotted temperatures, measured from both FBG (blue circles) and TC (red lines), during 150 hours calibration process.
With calibrated FBG sensors, the thermal stability or drifting trend has been studied under an isothermal condition. Figure 3 has shown the measured wavelength and FBG peak power stability at $650^{\circ} \mathrm{C}$ for degradation and lifetime estimations. The data (circles) in Figure 3(a) has shown a trend of the wavelength shift is $\sim 5.4 \times 10^{-6} \mathrm{~nm} / \mathrm{hr}$. at $650^{\circ} \mathrm{C}$, and that of $\mathrm{FBG}$ peak power loss is about $-(5$ to 20) $\times 10^{-5} \mathrm{dBm} / \mathrm{hr}$. If ignoring any oven thermal drift arising from PID-controlled K-Type TC feedback control, one can attribute such a trend as FBG sensor long-term thermal trend. If using approximate temperature sensitivity of $0.015 \mathrm{~nm} /{ }^{\circ} \mathrm{C}$ for $T>600^{\circ} \mathrm{C}$, the thermal variation caused temperature error is about $\pm 0.4^{\circ} \mathrm{C}$ per 1000 hours at $650^{\circ} \mathrm{C}$. Note that these estimated thermal drifts are within K-Type TC accuracy range of $\pm 0.4 \%$, namely, $\pm 2.5^{\circ} \mathrm{C}$ at $650^{\circ} \mathrm{C}$. On the other hand, the measured FBG peak power loss trend could be used to estimate the lifetime of the $\mathrm{FBG}$ sensor at $650^{\circ} \mathrm{C}$ operation. If the FBG peak power degradation is at a rate of $-(5-20) \times$ $10^{-5} \mathrm{dBm} / \mathrm{hr}$, it will lose $0.44-1.76 \mathrm{dBm}$ per year. A common quality of an FBG sensor is of a typical peak power of $25 \mathrm{dBm}$; the corresponding time for losing $25 \mathrm{dBm}$ peak power will take 10 more years.

However, the real lifetime of the FBG actually strongly depends upon external environment conditions and mechanical package. On the other hand, the linearly estimated lifetime could be underestimated if the degradation trend is nonlinear. In normal case, a lifetime of 3-6 years is required for industrial machinery system application.

\section{Fiber Temperature Sensor Package and Installation}

In order to install FBG sensor for high-density temperature profile measurement from a gas turbine engine or from a compressor interstage, the operation within such a harsh environment requires the fiber sensors to be packaged for reliability. Consequently, a fiber sensor package should be hermetically sealed for maintaining strong mechanical integrity against vibration, thermal cycles, and stresscorrosion-induced mechanical fatigues. This is not only due to fiber fragility itself but also due to the detrimental longterm effect of corrosive gases, moisture, and acidic and alkaline chemicals potentially attacking the sensors. In addition, a proper sensor package will not impede dynamic thermal measurement during gas turbine startup transient. Since each industrial system application may vary in temperature, pressure, flow rate, vibration, and corrosion, for example, the sensor packages may differ from one industrial system to another industrial system and survive different harsh environmental conditions.

FBG temperature sensors can be installed at precombustor flow path, turbine inlet, downstream of the combustor or exhaust, and interstage locations for measuring dynamic temperature anomalies. Presurge condition in a turbine engine causes abnormal temperature fluctuation in the gas phase. Key measurements for surge control are suction/discharge temperature and pressure and flow rate through the compressor. The FBGs can be positioned at 


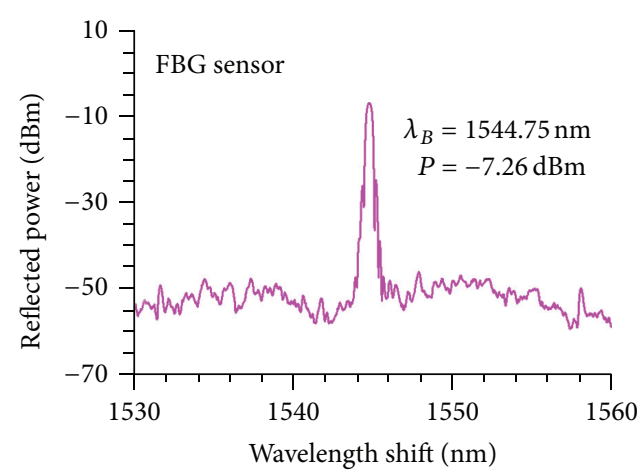

(a)

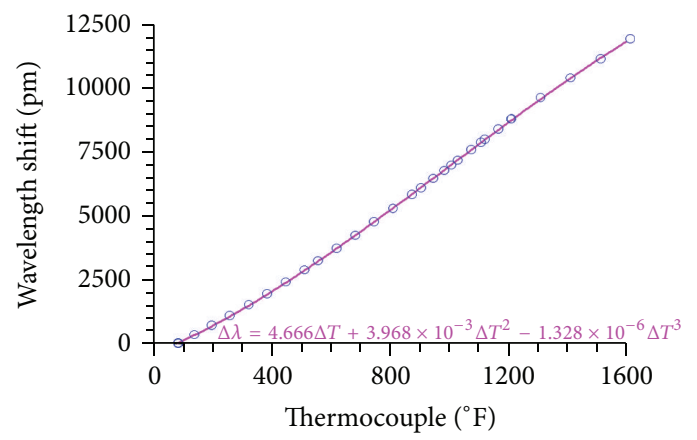

(c)

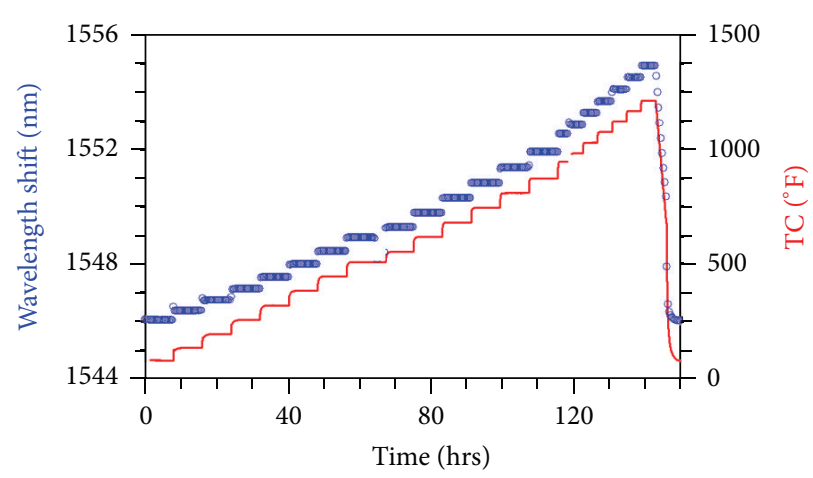

(b)

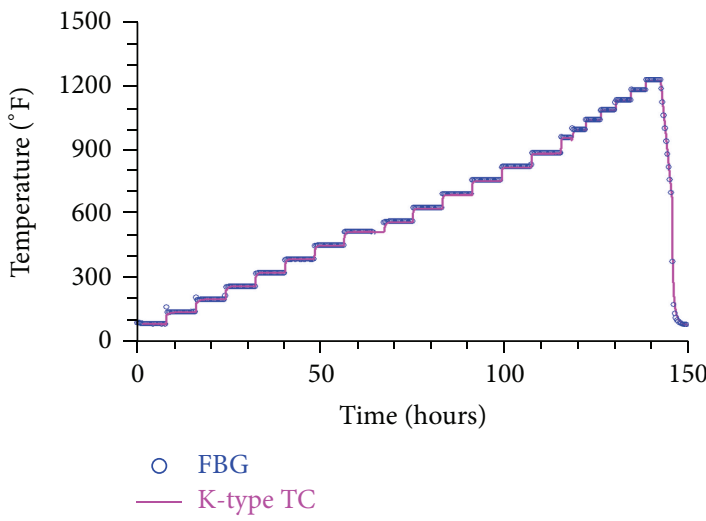

(d)

FIGURE 2: Fiber sensor calibration process for converting the measured Bragg resonant wavelength shift to temperature.

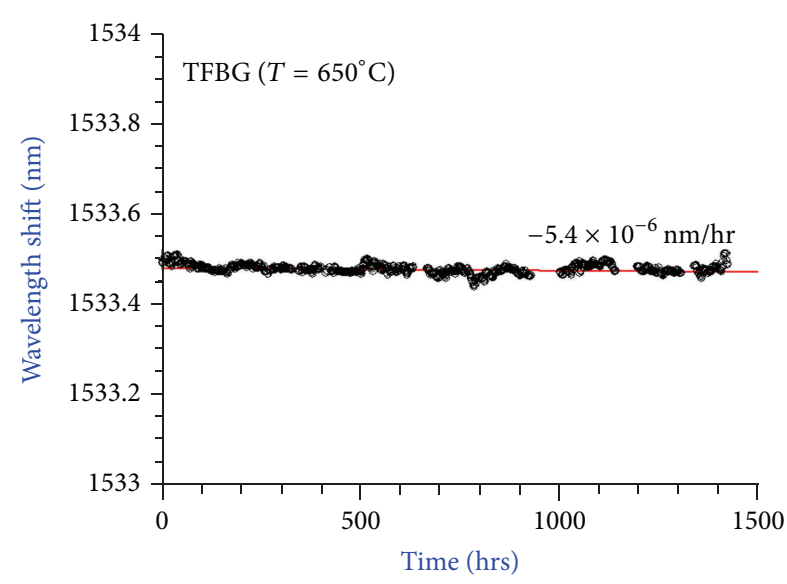

(a)

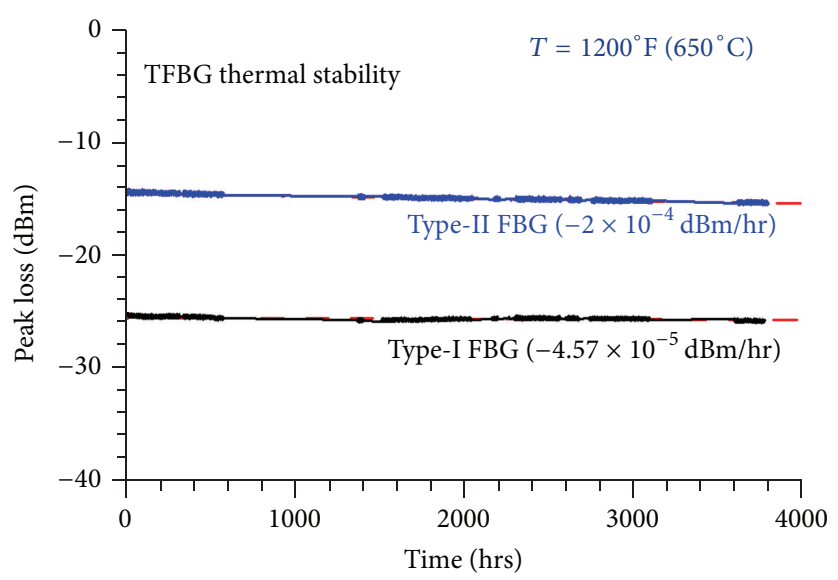

(b)

Figure 3: Short-term measured FBG sensor thermal stability (a) and FBG peak power loss at $650^{\circ} \mathrm{C}$.

multiple locations in the compressor. For example, the FBG temperature sensor installed around the periphery of the turbine engine air inlet could detect presurge temperature spikes. In addition, the fiber sensing array may be installed in the pre-combustor flow path, downstream of the combustor, turbine engine inlet, and between the compressor stages. If the fiber sensors are installed in the turbine exhaust duct, it will enable the monitoring temperature variation that provides a means of detecting combustor health. This measured temperature combined with pressure enables better diagnostics and compressor surge protection.

Two fiber sensor packages have been designed for gas turbine exhaust temperature measurement. First one is a cable based for circumferential exhaust temperature detection, in which the FBG elements are inscribed onto three fibers and sealed inside an Inconel 625 tube, as described by [15]. The 


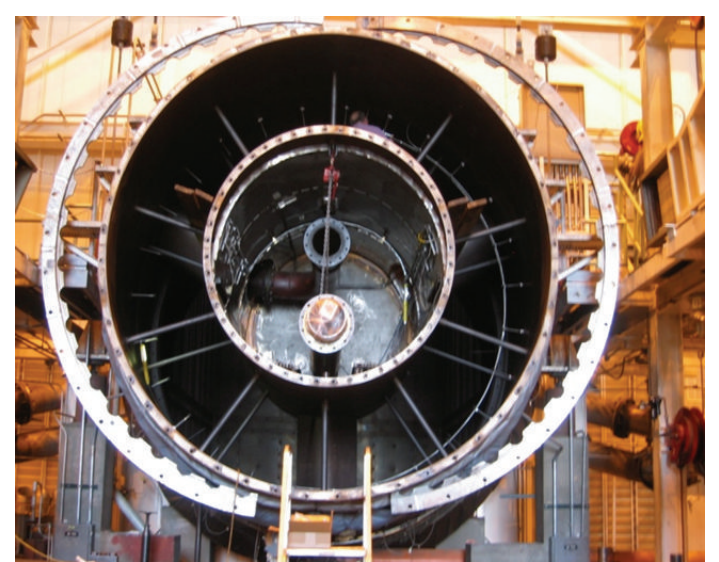

(a)

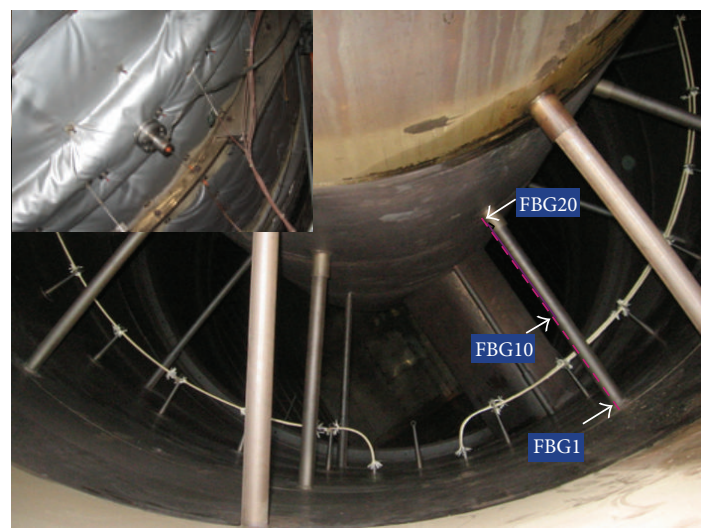

(c)

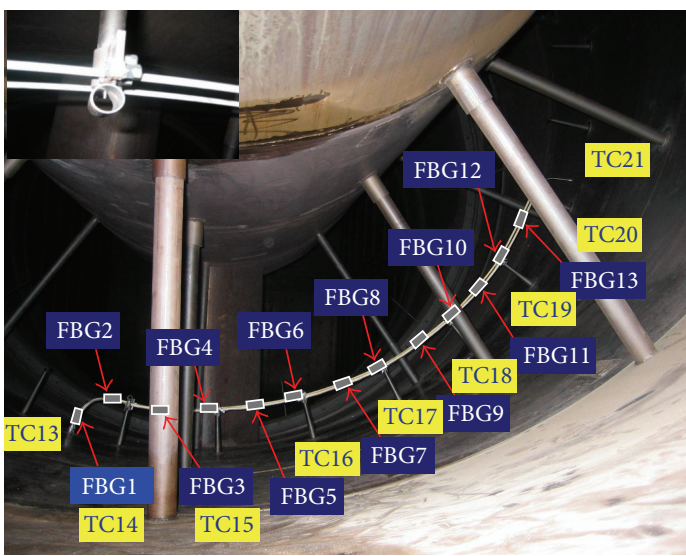

(b)

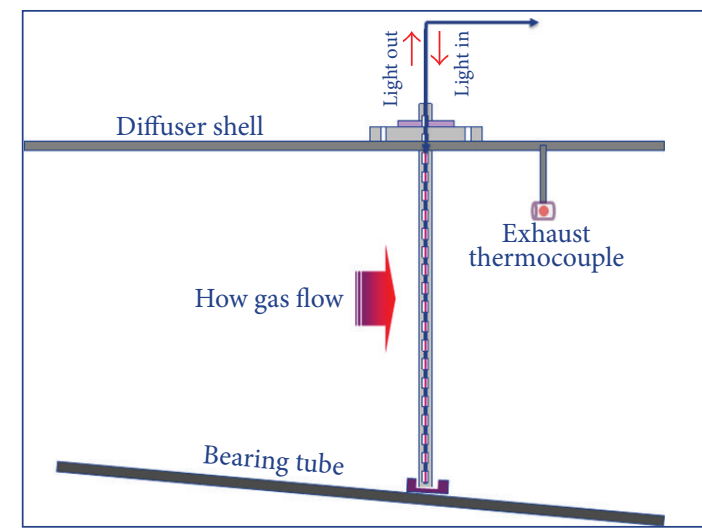

(d)

FIGURE 4: Fiber sensor installation in the gas turbine exhaust duct with circumferential fiber sensing cable in (a) and (b) and with fiber sensing rake in (c) and (d).

second one is based on a precision exhaust temperature rake with FBG sensors attached to its surface.

This integrated radial sensing rake has $100 \mathrm{~mm}$ spatial resolution across exhaust duct wall to central barrier space, described by [15]. Figure 4 shows two configurations for measuring both static and dynamic gas turbine exhaust temperature response. For addressing the entitlement of the FBG sensor performances in accuracy, reliability, and durability as a backup candidate technology of the existing thermocouple sensor, a fiber sensing cable is installed close to the existing exhaust thermocouples with a circumferential configuration, as shown in Figures 4(a) and 4(b). For evaluating dynamic performance in response time to transient operation condition variation, a fiber sensing rake is installed in a gas turbine that can measure radial exhaust temperature from diffuser to central bearing tube, as shown in Figures 4(c) and 4(d). A 1$5 \mathrm{~Hz}$ optical sensing interrogator with 4 channels capability is used to detect static signal, while a $1000 \mathrm{~Hz}(1 \mathrm{~ms})$ optical sensing interrogator is used for dynamic signal detection.

For circumferential exhaust temperature detection, FBG elements are inscribed onto a single fiber with a spatial separation of $450 \mathrm{~mm}$; three sensing fibers with $150 \mathrm{~mm}$ misplacement provide double spatial resolution for gas turbine exhaust temperature profile detection. The obtained wavelength data are converted to temperatures with a precalibrated transfer function that enables the measured FBG sensor static data to be compared with the thermocouple sensors. The fiber sensing cable is clamped to an existing radiation TC shield with entrances holes in between two thermocouples [15]. The down selection of a metal tube geometry and size has been determined with a simulation that has focused on thermal stress severity, mechanical strength, and natural vibration frequency of the metal tube. Since rotor blade rotation speed is $3600 \mathrm{rpm}$ for a $60 \mathrm{~Hz}$ gas turbine and $3000 \mathrm{rpm}$ for a $50 \mathrm{~Hz}$ gas turbine, its fundamental, first and second high-order vibration frequencies range from 50 to $300 \mathrm{~Hz}$. To avoid an overlap between the natural vibration frequency of the metal tube packaged fiber sensing cable and gas turbine's vibration band, the modeling has shown that an Inconel tube could meet such a requirement with appropriate diameter and wall thickness.

For radial exhaust temperature detection, a precision exhaust temperature rake is used to support FBG sensors as an integrated radial sensing rake. There are $9 \mathrm{TCs}$ that are embedded into the rake with a $\varnothing 3 \mathrm{~mm}$ open hole to enable hot gas to pass through the hole for TC measuring hot gas temperature. However, the fiber sensing array is sealed in a fine-gage Inconel 625 tube, which is welded onto the rake 
surface with one-to-one correspondence between the FBG and TC location. Since the Inconel tube is attached to the rake surface and faces the hot gas flow, the combustion-dynamicsinduced transient total temperature, $T_{t}(t)$, is proportional to flow velocity by

$$
T_{t}(t)=T_{S}(t)+\frac{v(t)^{2}}{2 c_{p}},
$$

where $T_{S}(t)$ is static temperature, $c_{p}$ is gas-specific heat coefficient, and $v(t)$ is transient gas flow velocity. When FBG sensors are used to measure both static and total temperatures with (4), the gas flow velocity or combustion-induced flow dynamics can be directly measured by

$$
\begin{aligned}
& v(t)=\frac{2 c_{p}}{\kappa_{T}(0)}\left(\Delta \lambda\left[T_{t}(t)\right]-\Delta \lambda\left[T_{S}(t)\right]\right)^{1 / 2} \\
& \text { Vortex shedding frequency } \propto \text { FFT } \\
& \qquad\left\{\frac{2 c_{p}}{\kappa_{T}(0)}\left(\Delta \lambda\left[T_{t}(t)\right]-\Delta \lambda\left[T_{S}(t)\right]\right)\right\} .
\end{aligned}
$$

The static temperature corresponds to exhaust temperature with flow velocity close to zero, or near duct boundary layer. The vortex shedding frequency can be used to indirectly characterize the flow characteristics using Strouhal number, which is determined by frequency $*$ length/velocity. It is clear that the fast Fourier transform of the differentiation of static and dynamic signals could be used to correlate to different dynamic events and parameters, such as antisurge, turbine blade rotation speed variation, and combustion dynamics, and so forth. For example, when fuel quality changes, it leads to gas-specific heat $\left(c_{p}\right)$ variation or vortex shading frequency variation. To measure dynamic FBG response to turbine operation condition, it normally requires high-band optical sensing interrogator that ranges from $1 \mathrm{kHz}$ to $100 \mathrm{kHz}$.

\section{Fiber Sensor Response to Static Exhaust Temperature}

During a typical gas turbine factory test, different instruments will monitor various parameters, such as cranking motor output, turbine HP shaft speed, fuel stroke reference, IGV angle, averaged compressor inlet temperature, vibration amplitude, turbine exhaust static pressure, and air flow to fully characterize a gas turbine's performance before its delivery to customer. Corresponding to this baseline performance test, the gas turbine is under full speed without loading test. Figure 5 is a typical test from the fiber sensing rake with $20 \mathrm{FBG}$ sensors. Since the fiber sensing rake is an integration of the existing exhaust precision temperature rake and FBGs, there are also nine TCs inside the rake as a reference. Since the first 3 FBGs are close to gas turbine diffuser wall, the boundary layer flow near the wall surface causes the measured temperature to be lower than the others. In Figure 5(b), these averaged TCs are plotted against additional 17 FBGs. To see details from both TC and FBG sensors, Figures 5(c) and $5(d)$ have plotted measured temperature during the steadystatus operation condition.
Five of nine TCs data have been shown about $5^{\circ} \mathrm{F}$ variation during $100 \mathrm{~min}$ steady operation time while fiber sensors have shown about $9-10^{\circ} \mathrm{F}$ variation. This discrepancy is due to the fact that the TCs are located inside the rake with an open hole of $\sim \phi 3 \mathrm{~mm}$, and the fiber sensing tube is welded to the rake surface across nine holes. Another potential origination could reflect the nature of the total temperature measured by the fiber sensors in contrast to the static temperature measured by the TCs. Meanwhile, the fiber sensors have shown comparable noise characteristics with respect to the TCs, which may relate to flow rate variation during state status operation.

Figure 6 has further shown the measured temperature profile from a full test of nearly 7 hours from a 7FB gas turbine manufacturing qualification process. The exhaust temperature from circumferential fiber sensing cable can be plotted in 3D as shown in Figure 6(a). During the startup stage of the gas turbine, performance monitoring is done via a polar diagram to highlight anomalies quickly. As shown in Figure 6(b), the measured exhaust temperature appears not to be uniform across 27 TCs. The FBG sensor at 170 locations also indicates the same anomalous variation. It is noticeable that the thermal profile is not symmetrical and it is very likely due to varied can-to-can combustion and hot gas flow variation. In addition, the dynamic process during startup provides variation as compared to steady base load operation which shows up on the polar diagram as temperature variation. It is clear that both $3 \mathrm{D}$ thermal profile and polar diagram measured with high-density fiber sensors could provide directly information on the gas turbine performance, which are comparable to the data measured from existing exhaust thermocouples.

\section{Fiber Sensor Response to Dynamic Process}

The fiber sensing rake and surface-attached fiber sensors have shown to be comparable to standard production TCs and also to be more sensitive to dynamic processes. This is illustrated by the fiber sensor response amplitude as shown in Figure 7. Since the first FBG is close to exhaust diffuser duct, its response amplitude is relatively small but with the increase of the radial distance towards the internal bearing tube, the dynamic amplitudes of the FBGs have shown corresponding increase. This increased amplitude mainly arises from the startup transient process with increased fuel gas flow, combustion dynamics, and pressure variation from compressor to gas turbine exhaust. However, the dynamic amplitude may be used for monitoring anomalous structural instability, presurge, and incomplete combustion events. For monitoring these dynamic events, the relative dynamic amplitude is more important than the absolute exhaust temperature measurement.

The other critical dynamic response feature of the fiber sensor is illustrated in Figure 8, where the FBG sensor's dynamic temperature response is plotted against the same location TC data as a function of time during first several minutes during the gas turbine startup transient. The small difference could be due to hot gas flow variation induced sensing rake oscillation or strain effect. 


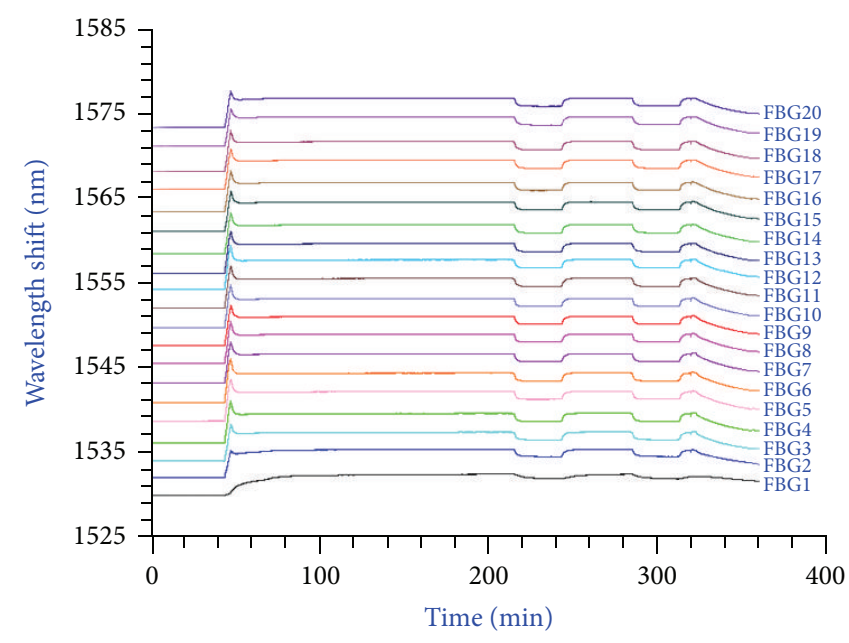

(a)

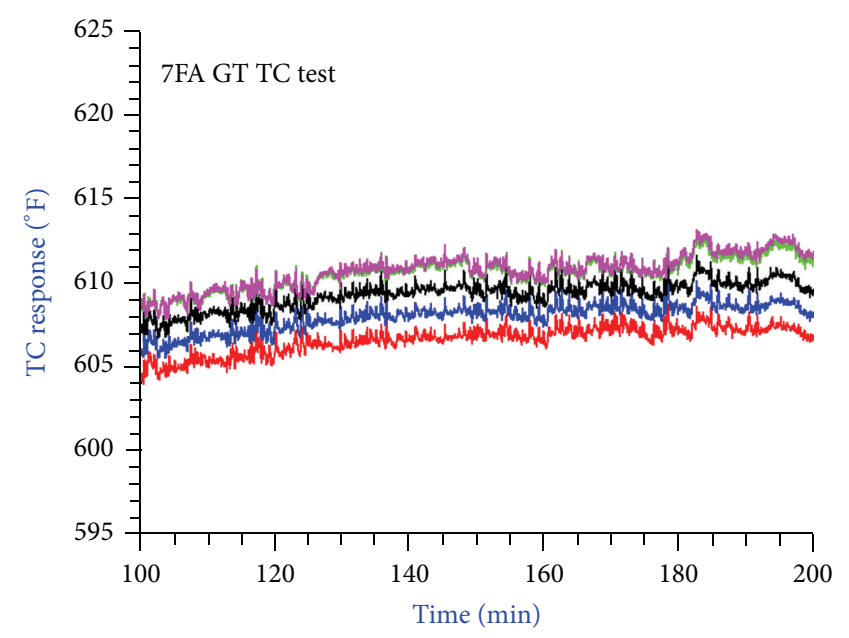

(c)

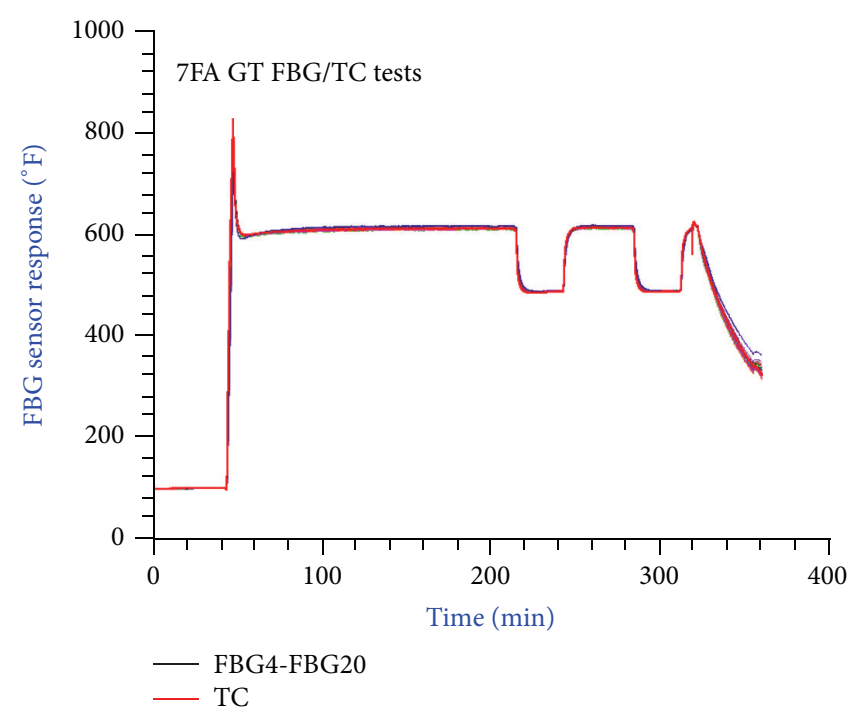

(b)

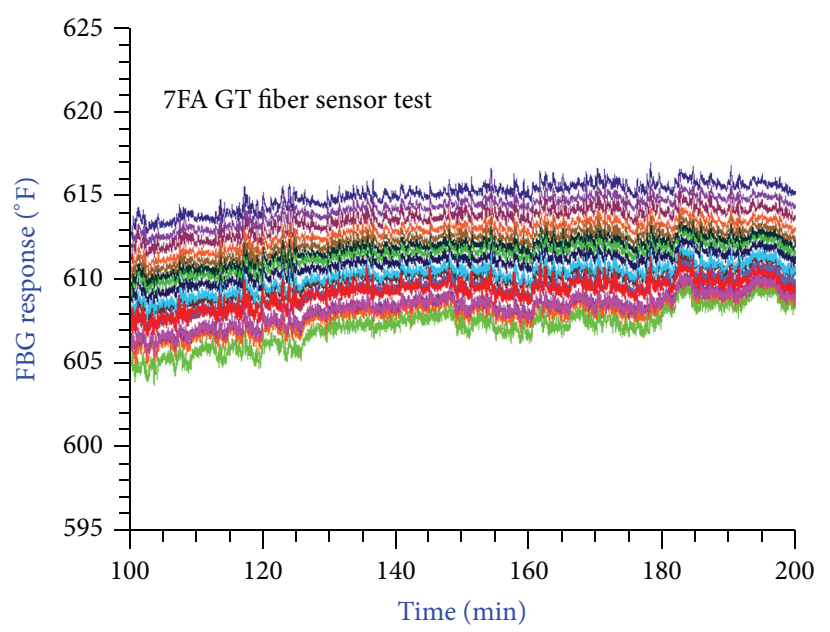

(d)

FIGURE 5: Fiber sensor and TC measured exhaust temperatures during a 7FA GT test with radial fiber sensing rake.

In addition, Figure 9 shows the dynamic response of the fiber sensors after leaving the transient startup condition. The bottom power spectra of the Figure 9 clearly show that the gas turbine cranking process has a high-level inharmonic oscillation. At gas turbine startup, the measured frequency is close to $60 \mathrm{~Hz}$ of the gas turbine blade rotation speed, but it gradually shifts to exhaust rake natural vibration frequency of $\sim 40 \mathrm{~Hz}$ during steady-status operation. Such a dynamic response could be leveraged as a precursor for determining the health of the gas turbine. Thermal response of the FBG sensors can be used similar to annular array of thermocouples as a sensor input for fuel control to the combustion system. The dynamic temperature and power spectra can be utilized for antisurge, gas volumetric flow rate, combustion efficiency, and turbine-blade-rotation-related structural instability analyses.

It is also important to note that the converted power spectra and associated vibration mode profile can be used for gas turbine long-term performance degradation analysis.
One of the features is its broad frequency band profile and its response amplitude. With increase vibration, mechanical issue becomes more of a concern, which may cause the gas turbine to degrade at an increased rate. These mechanical issues could come from the torque variation between the compressor and turbine coupling, rotor blade vibration and tip clearance change, bearing wearing, bucket parts loosening. Another valuable feature is fiber sensor's multifunctional nature that can be used for simultaneously measuring dynamic and static temperature, while its response amplitude can be associated with various dynamic and transient responses that could be related to various mechanical, thermal, and electric variations.

\section{Conclusions}

Fiber-Bragg-grating-based sensing technology has been further developed and validated in power generation system, such as gas turbine, for operation condition monitoring. 


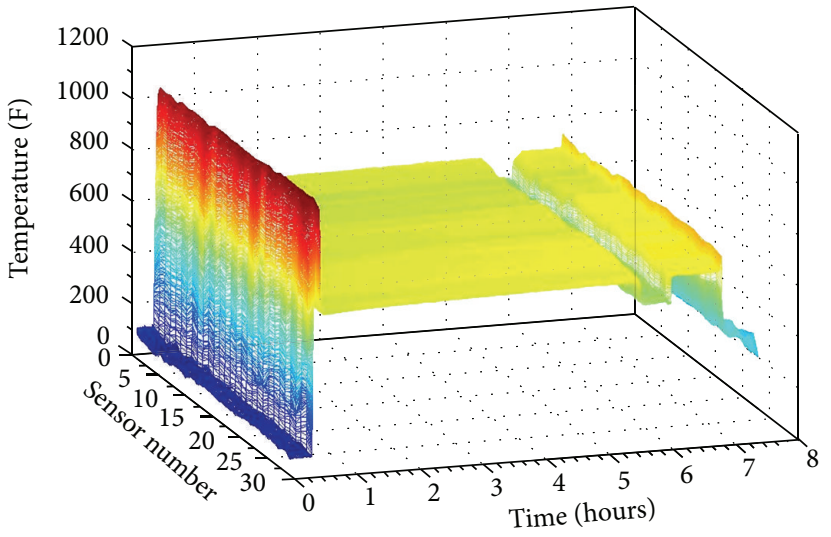

(a)

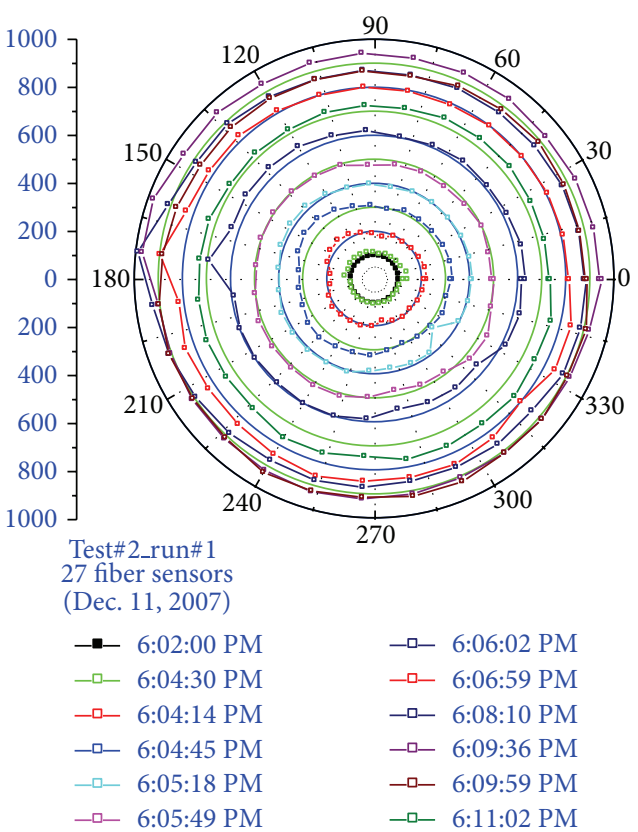

(b)

Figure 6: Exhaust thermal profile measured from a circumferential fiber sensing cable of 29 FBGs (a) and polar diagram of all the fiber sensors during a gas turbine startup process (b).

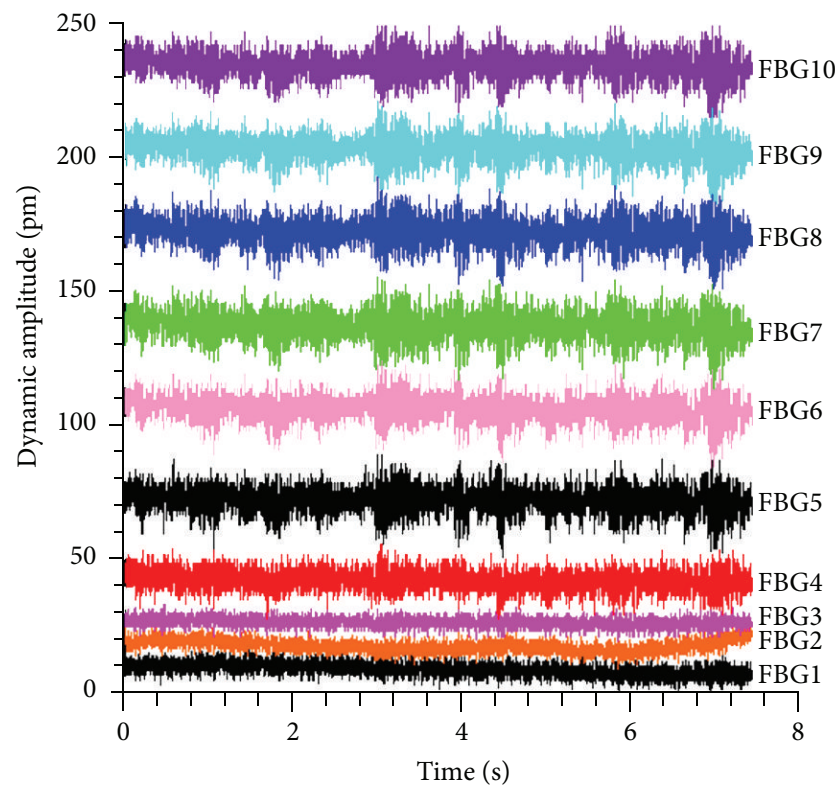

FIGURE 7: The measured dynamic response amplitude from FBG1 to FBG10 from a fiber sensing rake.

The fiber sensor has demonstrated its unique advantage in providing high-density, multipoint, and multifunction capability in measuring static and dynamic responses from a gas turbine. To meet industrial harsh environmental sensing needs, one of the critical engineering work is the fiber sensor package, which varies from one machinery system to another system. The fiber sensor package is not only

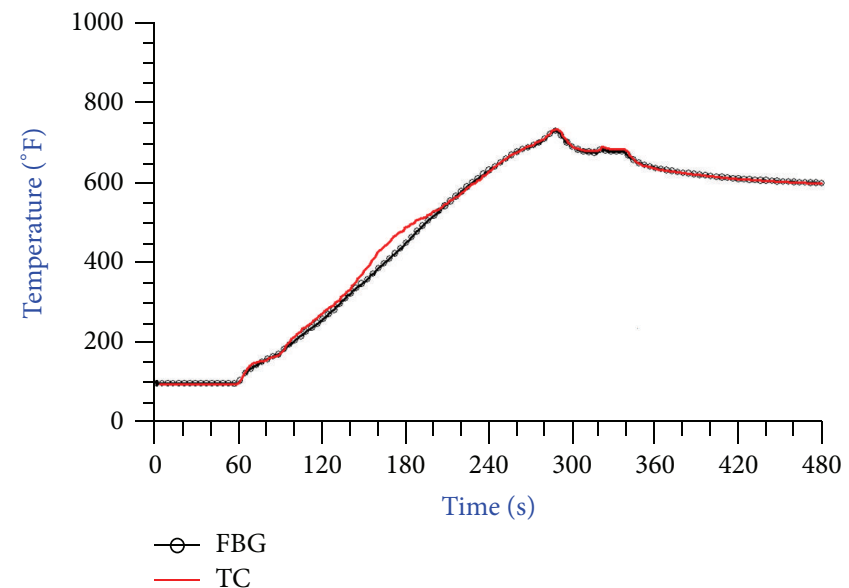

FIgURE 8: The transient response comparison between the fiber sensor and thermocouple from a 7FA gas turbine manufacturing qualification test.

required to provide accurate measurement but also to prevent mechanical strength degradation from elevated temperature, massive hot gas flow, and blade-rotation-related structural vibration. The work presented in this paper is to demonstrate a new test/measurement technology that also can be used to measure multipoint temperature from a gas turbine with only one fiber sensing cable and one penetration. This fiber sensing method discussed herein is not limited to gas turbine exhaust temperature measurement. Its unique multifunction, static and dynamic responses, and distributed sensing capabilities make the high-density fiber sensor more valuable for 


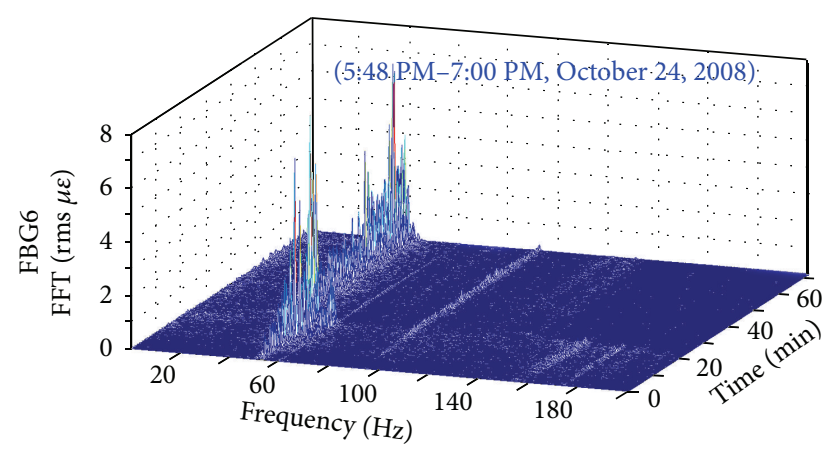

(a)

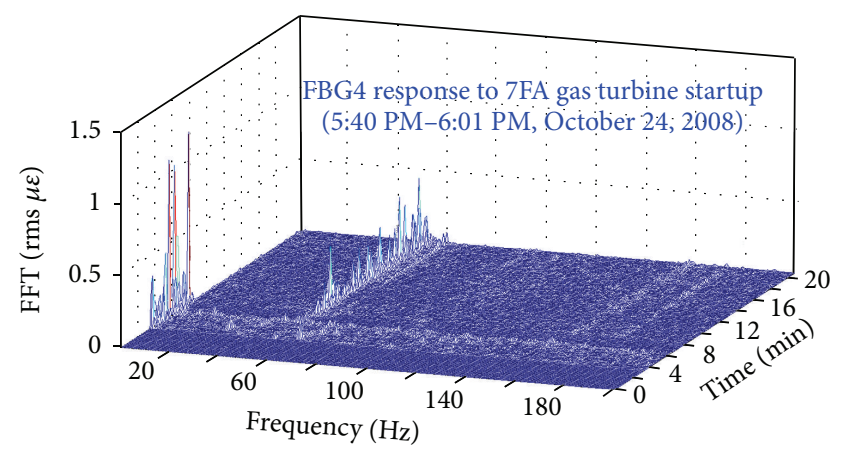

(b)

FIGURE 9: Fiber sensor measured dynamic signal and corresponding power spectra from 7FA gas turbine startup transient qualification test.

next-generation power generation turbomachinery system operation with respect to condition monitoring, diagnostics, control, and optimization.

\section{Acknowledgments}

During this development work, Kevin McCarthy, Juntao Wu, Renato Guida, Mohamed Sakami, Jerry Lopez, Alex Ross, David O'Connor, C. Wagner, James Nutt, Ronald Gilstrap, and Mike Krok have been involved in many fundamental research, laboratory test work, field sensor installations, and validations.

\section{References}

[1] K. O. Hill, Y. Fujii, D. C. Johnson, and B. S. Kawasaki, "Photosensitivity in optical fiber waveguides: application to reflection filter fabrication," Applied Physics Letters, vol. 32, no. 10, article 647, 3 pages, 1978.

[2] M. Fokine, "Underlying mechanisms, applications, and limitations of chemical composition gratings in silica based fibers," Journal of Non-Crystalline Solids, vol. 349, no. 1-3, pp. 98-104, 2004.

[3] S. Pal, T. Sun, K. T. V. Grattan et al., "Strain-independent temperature measurement using a type-l and type-IIA optical fiber Bragg grating combination," Review of Scientific Instruments, vol. 75, no. 5, pp. 1327-1331, 2004.

[4] H. Xia, K. McCarthy, and C. M. Young, "Harsh environment temperature sensing system and method," US Patent 7912334, 2011.

[5] D. Barrera, V. Finazzi, J. Villatoro, S. Sales, and V. Pruneri, "Packaged optical sensors based on regenerated fiber bragg gratings for high temperature applications," IEEE Sensors Journal, vol. 12, no. 1, pp. 107-112, 2012.

[6] H. Guo, G. Xiao, N. Mrad, and J. Yao, "Fiber optic sensors for structural health monitoring of air platforms," Sensors, vol. 11, no. 4, pp. 3687-3705, 2011.

[7] L. Hui and O. Jinping, "Structural health monitoring: from sensing technology stepping to health diagnosis," Procedia Engineering, vol. 14, pp. 753-760, 2011.

[8] B. Zhang, "High-temperature resistance fiber bragg grating temperature sensor fabrication," IEEE Sensors Journal, vol. 7, no. 4, pp. 586-591, 2007.
[9] J. Canning, S. Bandyopadhyay, M. Stevenson, and K. Cook, "Fiber Bragg grating sensor for high temperature application," in Proceedings of the Opto-Electronics and Communications Conference and the Australian Conference On Optical Fibre Technology (OECC/ACOFT '08), July 2008.

[10] G. Brambilla, "High-temperature fibre Bragg grating thermometer," Electronics Letters, vol. 38, no. 17, pp. 954-956, 2002.

[11] H. Xia, "Advanced fiber optical sensor and instrumentation for power generation industrial monitoring and diagnostics," in Fiber Optic Sensors and Applications, vol. 8370 of Proceedings of SPIE, 2012.

[12] B. Zhang and M. Kahrizi, "High temperature resistance temperature sensor based on the hydrogen loaded Fiber Bragg grating," in Proceedings of the IEEE Conference on Sensors, pp. 624-627, November 2005.

[13] J. Li, D. Zhang, X. Wen, and L. Li, "Fabrication and temperature characteristics of thermal regenerated fiber bragg grating," in Proceedings of the Symposium on Photonics and Optoelectronics (SOPO '12), pp. 1-4, 2012.

[14] H. Xia, "Fiber Bragg grating and fabrication method," US Patent 7574075, 2009.

[15] H. Xia, K. McCarthy, J. Nutt et al., "Bragg grating sensing package and system for gas turbine temperature measurement," US Patent 8306373, 2012. 

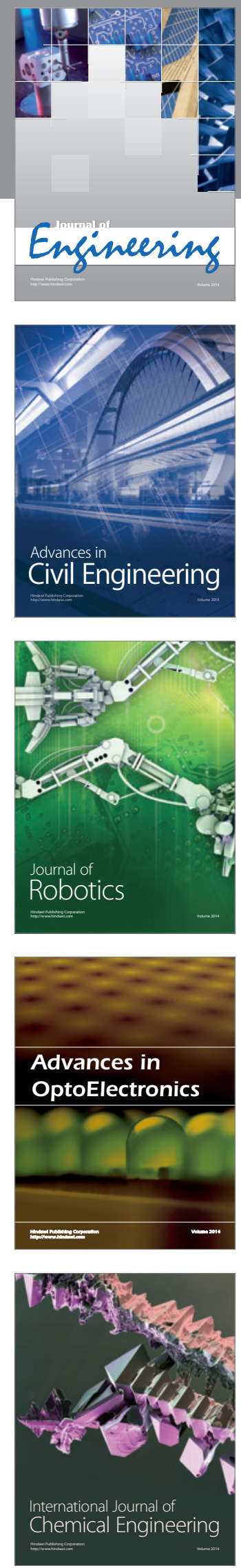

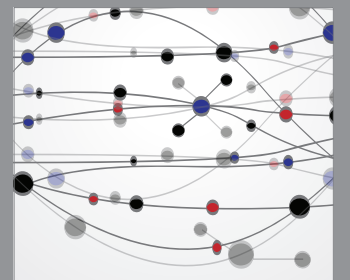

The Scientific World Journal
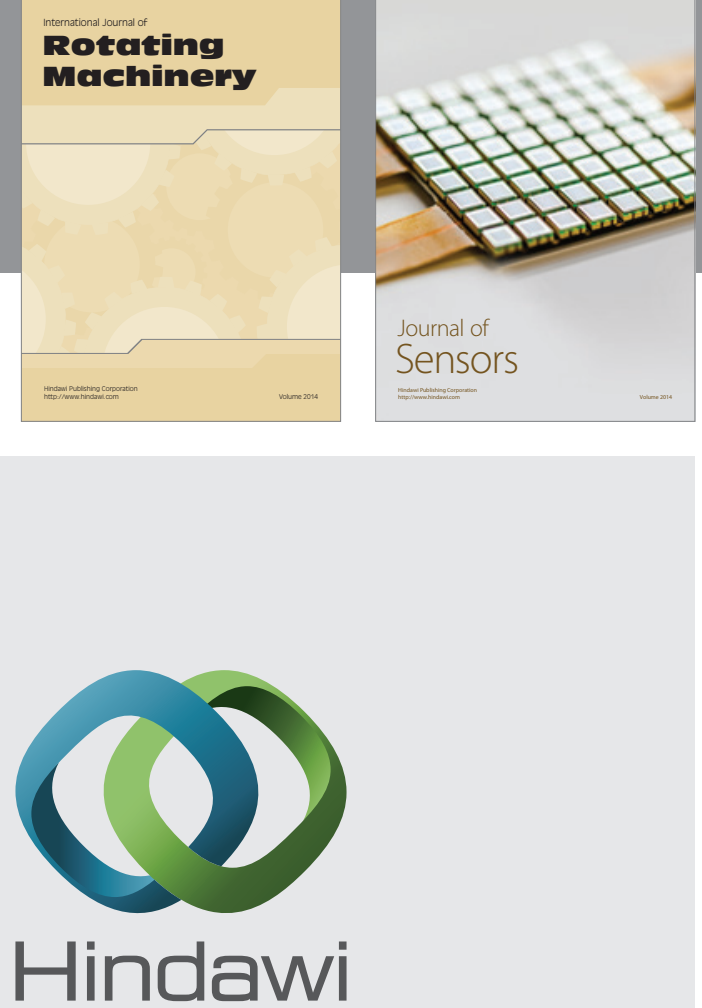

Submit your manuscripts at http://www.hindawi.com
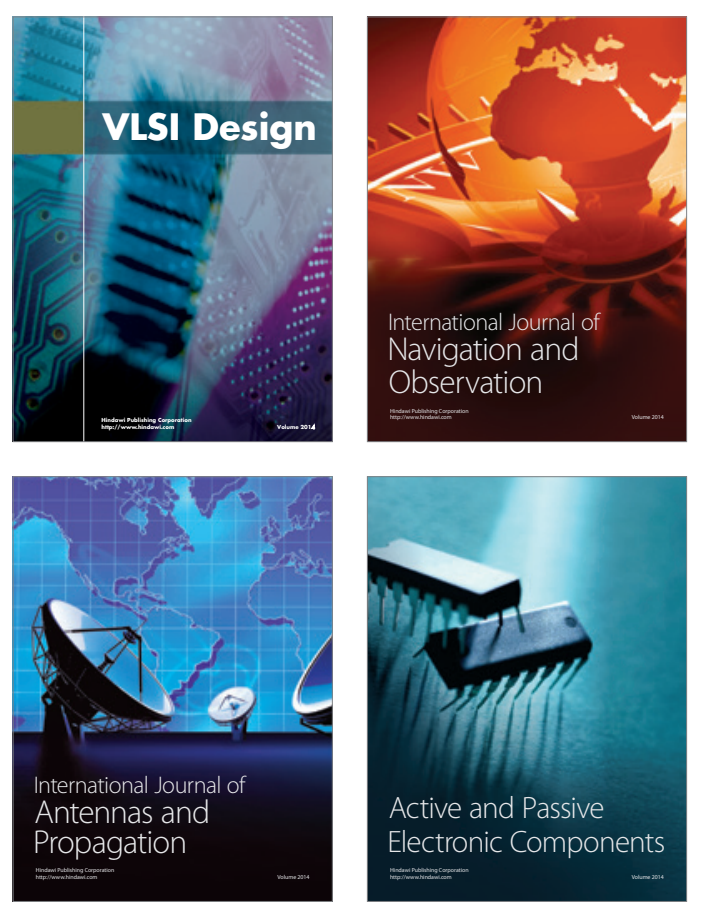
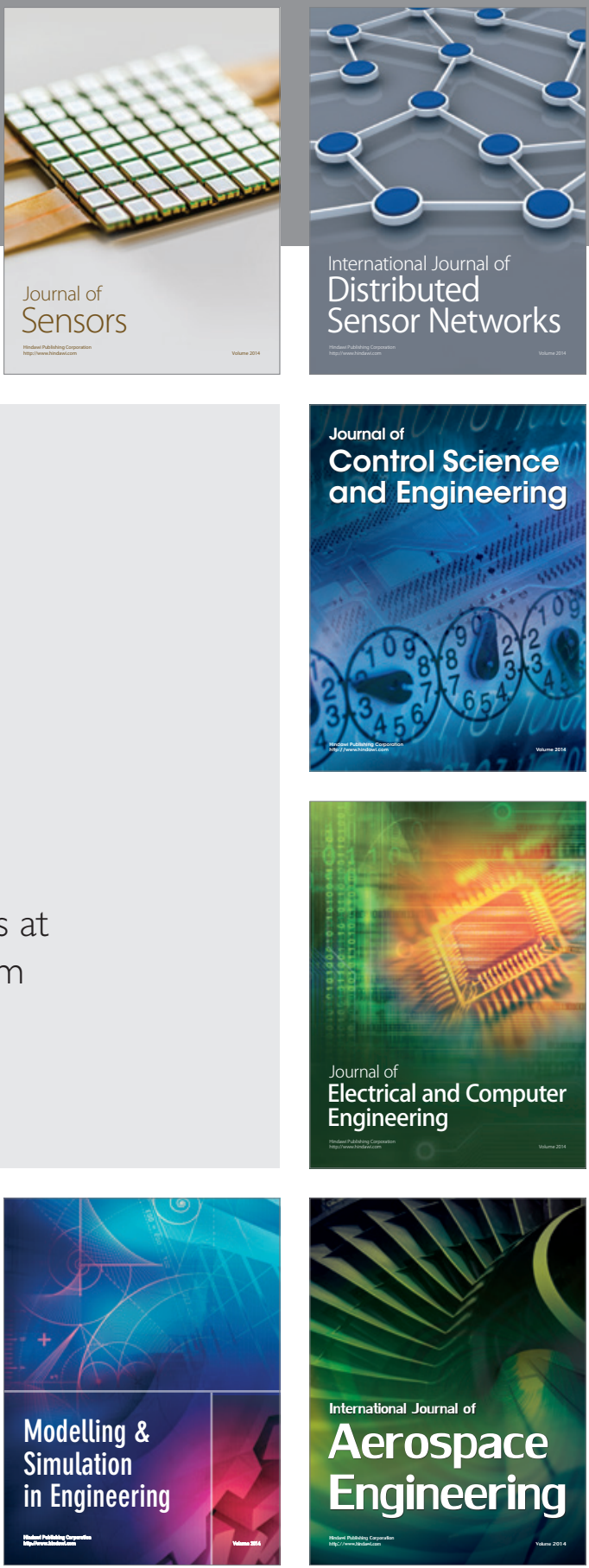

Journal of

Control Science

and Engineering
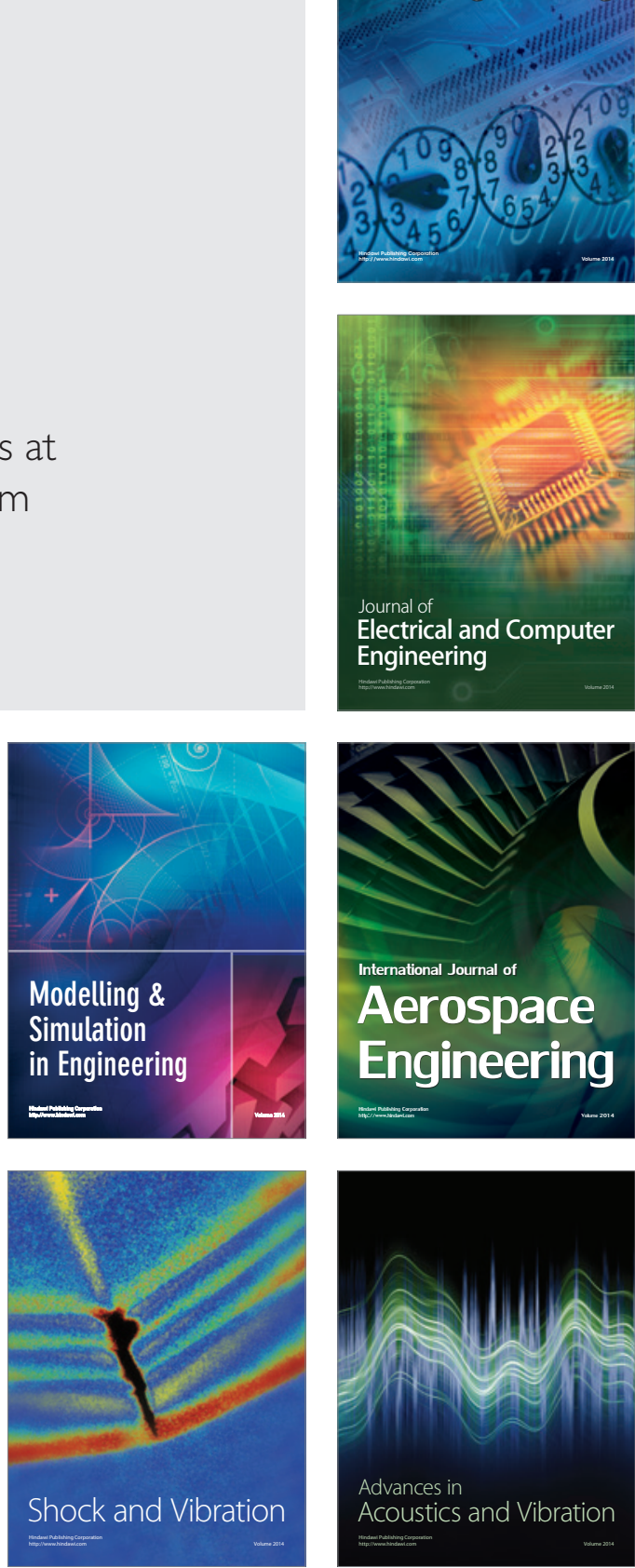